\title{
Somatic Type Delusional Disorder
}

National Cancer Institute

\section{Source}

National Cancer Institute. Somatic Type Delusional Disorder. NCI Thesaurus. Code C94387.

A subtype of delusional disorder characterized by the central delusional theme that the individual has some physical defect or medical condition. 